\title{
(อ) OPEN ACCESS \\ Starting school: educational development as a function of age of entry and prematurity
}

\author{
Katherine J Pettinger (D) , ${ }^{1}$ Brian Kelly, ${ }^{1}$ Trevor A Sheldon, ${ }^{1,2}$ Mark Mon-Williams, ${ }^{1,3}$ \\ John Wright, ${ }^{1}$ Liam J B Hill ${ }^{1,3}$
}

- Additional material is

published online only. To view please visit the journal online (http://dx.doi.org/10.1136/ archdischild-2019-317124).

${ }^{1}$ Bradford Institute for Health Research, Bradford, UK ${ }^{2}$ Department of Health Sciences, University of York, York, UK ${ }^{3}$ School of Psychology, University of Leeds, Leeds, UK

\section{Correspondence to}

Dr Katherine J Pettinger, Bradford Institute for Health Research, Bradford BD9 6RJ, UK; katherinepettinger@gmail.com

Received 26 February 2019 Revised 16 June 2019 Accepted 24 June 2019 Published Online First 13 August 2019

\section{ABSTRACT \\ Objective To estimate the impact on early development of prematurity and summer birth and the potential 'double disadvantage' created by starting school a year earlier than anticipated during pregnancy, due to being born preterm.}

Design, setting and patients We investigated the impact of gestational and school-entry age on the likelihood of failing to achieve a 'Good Level of Development' (GLD) on the Early Years Foundation Stage Profile in 5-year-old children born moderateto-late preterm using data from the Born in Bradford longitudinal birth cohort. We used hierarchical logistic regression to control for chronological maturity, and perinatal and socioeconomic factors.

Results Gestational age and school-entry age were significant predictors of attaining a GLD in the 10337 children who entered school in the correct academic year given their estimated date of delivery. The odds of not attaining a GLD increased by $1.09(95 \% \mathrm{Cl} 1.06$ to 1.11) for each successive week born early and by 1.17 for each month younger within the year group $(95 \% \mathrm{Cl}$ 1.16 to 1.18). There was no interaction between these two effects. Children starting school a year earlier than anticipated during pregnancy were less likely to achieve a GLD compared with (1) other children born preterm (fully adjusted OR 5.51 (2.85-14.25)); (2) term summer births (3.02 (1.49-6.79)); and (3) preterm summer births who remained within their anticipated school-entry year (3.64 (1.27-11.48)).

Conclusions These results confirm the developmental risks faced by children born moderate-to-late preterm, and — for the first time-illustrate the increased risk associated with 'double disadvantage'.

\section{OBJECTIVES}

Gestational age has been shown to be inversely proportional to the prevalence of special educational needs (SEN), ${ }^{1}$ and children born preterm ( $<37$ weeks' gestation) are at risk of developmental problems, as indexed by below-average attainment and higher levels of SEN at age 7 years and above. ${ }^{2-4}$ Intervention and support are often concentrated on children born extremely preterm though: in the UK enhanced surveillance and follow-up are only offered routinely for children born before 30 weeks' gestation. ${ }^{5}$ This is despite evidence that children born moderate-to-late preterm (32-36 weeks' gestation) are still at increased risk of poorer later development. $^{6}$

Prematurity is one of many factors that determine the odds of a child showing good development.

\section{What is already known on this topic?}

- Chronologically younger, summer-born children have worse educational outcomes compared with older children within their academic year.

- Prevalence of special educational needs is inversely proportional to gestational age.

- These differences have previously been demonstrated largely from 7 years old and upwards.

\section{What this study adds?}

- This is the first study to quantify the risk of poorer educational performance at 5 years of age if born preterm.

- Children born preterm who consequently enter school a year 'early' are 'doubly disadvantaged' due to reduced chronological and gestational age compared with their peers.

- School-entry age per se does not appear to moderate the risks posed by reduced gestational age.

Another notable factor is a child's age at the time they start school, determined in most countries by a cut-off linked to the start of the school year. Norbury et $a l^{7}$ found that a child's risk of not attaining a good level of development (GLD) at the end of the first year of mandatory schooling increased for every month born later in the academic year. ${ }^{7}$ For some children, the issue of school-entry age is connected to gestational age; premature birth can result in a child starting school a year earlier than expected during pregnancy. These children may face a 'double disadvantage' of relative immaturity at school entry due to both gestational and chronological age.

There is a need to better understand the impact that gestational age has on children's developmental readiness for school in cases of prematurity and determine how this adds to, or interacts with, the effect of a child's chronological maturity. Such insights would enable health and education providers to develop more evidence-based advice at this critical juncture and better support to children and their families.

We aimed to investigate whether there was an independent effect of both chronological age at school entry and gestational age and whether there was an interaction between them. We specifically 
sought to estimate the risks to early academic progress posed to children by entering school a year early due to preterm birth, by comparing them with other (1) children born preterm, (2) term summer births and (3) preterm summer births who remained within their anticipated academic year.

\section{DESIGN AND SETTING}

We used the rich data set afforded by the 'Born in Bradford' (BiB) longitudinal birth cohort study to address these issues. ${ }^{8} \mathrm{We}$ investigated the impact of gestational age on the likelihood of a child failing to achieve a 'Good Level of Development' following their first year of schooling (recorded using the Early Years Foundation Stage Profile, EYFSP).

\section{PARTICIPANTS}

For inclusion in this analysis, BiB participants had to have linked data available from hospital maternity and local authority educational records, regarding their gestational age at birth and child development at 5 years old. A comparison of the linked data used from this subsample, relative to the greater cohort, is reported in table 1. Data from 10390 children participating in $\mathrm{BiB}$ were used in our analyses. ${ }^{8}$ Participants had to have started school in the academic year expected given their birth date (ie, the September following their fourth birthday).

\section{Exposures}

Gestational age was measured in completed weeks. Gestational age was also compared with the estimated date of delivery to identify children for whom being born before term resulted in school entry an academic year earlier than anticipated during pregnancy, hereafter referred to as 'Early Academic Starts' (EAS).

\section{MAIN OUTCOME MEASURES}

The GLD measure from the EYFSP is the most widely used single measure of child development at 5 years old in the UK. ${ }^{9}$ An EYFSP assessment is completed for every child in state-funded, early-years education in England during the final term of the academic year in which they turn 5 . Teachers assess children's progress in each of the learning areas as 'emerging', 'expected' or 'exceeding'. In order to be classified as reaching a 'Good Level of Development', they must achieve either 'expected' or exceeding' in the prime learning areas of 'personal, social and emotional development', 'physical development', 'communication and language', as well as mathematics and literacy. ${ }^{9}$ Previous work has shown that summer-born children tend to score worse on these EYFSP items. ${ }^{79=}$

\section{Explanatory variables}

Perinatal factors

The mother's parity and child's month of birth, sex (male or female), and whether at birth they were classified as 'small' or 'large' for gestational age (SGA or LGA) were obtained from Bradford Royal Infirmary maternity records. 'Small' and 'large' categories were defined as falling either below the 10th percentile or above the 90th, respectively, on the WHO (UK) fetal growth charts for sex and gestational week at birth. This measure was only available for singleton births. Month of birth was transformed to reflect the month of birth relative to the start of the academic year (eg, September $=1$ st month...August $=12$ th month) and is hereafter referred to as 'Academic Month of Birth' (AMoB).
Table 1 Comparison of the demographics of all BiB participants with linked EYFSP and gestational age data compared with data available from the whole cohort

\begin{tabular}{|c|c|c|}
\hline & $\begin{array}{l}\text { EYFSP and } \\
\text { gestational age } \\
n=10390\end{array}$ & $\begin{array}{l}\text { Whole BiB cohort } \\
n=13818\end{array}$ \\
\hline Educational factors & & $10570^{*}$ \\
\hline EYFSP, n (\%) 'meeting GLD'† & $6161(59)$ & $6253(59)$ \\
\hline $\begin{array}{l}\text { English as an additional language, } \\
\mathrm{n}(\%)\end{array}$ & $4720(45)$ & $4788(45)$ \\
\hline Missing & $111(1)$ & $114(1)$ \\
\hline Perinatal factors & & $13525^{*}$ \\
\hline \multicolumn{3}{|l|}{ Gestational age (weeks), n (\%)‡ } \\
\hline$<32$ & $81(<1)$ & $149(1)$ \\
\hline $32-33$ & $65(<1)$ & $110(<1)$ \\
\hline $34-36$ & $478(5)$ & $646(5)$ \\
\hline $37-38$ & $2355(23)$ & $3028(22)$ \\
\hline $39-41$ & $7269(70)$ & $9047(67)$ \\
\hline$>42$ (late term) & $142(1)$ & $185(1)$ \\
\hline $\begin{array}{l}\text { Month of birth, } n(\%) \text { 'Summer } \\
\text { Born'§ }\end{array}$ & $3750(36)$ & $3816(36)$ \\
\hline Small for gestational age, $\mathrm{n}(\%)$ & 1449 (14) & $1857(14)$ \\
\hline Large for gestational age, $\mathrm{n}(\%)$ & $711(7)$ & $954(7)$ \\
\hline Sex ratio (male:female) & 49:51 & $52: 48$ \\
\hline Parity, median (range) & $1(0-10)$ & $1(0-10)$ \\
\hline Socioeconomic factors & & $11396^{*}$ \\
\hline $\begin{array}{l}\text { Mother receiving means-tested } \\
\text { benefits, } \mathrm{n}(\%)\end{array}$ & $3683(35)$ & $4639(41)$ \\
\hline Missing & $1859(18)$ & $39(<1)$ \\
\hline \multicolumn{3}{|l|}{$\begin{array}{l}\text { Maternal educational level } \\
\text { (equivalised), } \mathrm{n}(\%)\end{array}$} \\
\hline Higher than A level & $1991(19)$ & $2912(26)$ \\
\hline A level or equivalent & $1277(12)$ & $1644(14)$ \\
\hline 5 GCSEs or equivalent & $2717(26)$ & $3488(31)$ \\
\hline$<5 \mathrm{GCSEs}$ or equivalent & $1922(18)$ & $2453(22)$ \\
\hline Foreign unknown or other & $523(5)$ & $741(7)$ \\
\hline Unable to answer & $100(<1)$ & $128(1)$ \\
\hline Missing & $1860(18)$ & $30(<1)$ \\
\hline
\end{tabular}

${ }^{*} n$ within the whole cohort who consented and had linked records for this aspect of data collection.

†As defined by Cotzias and Whitehorn. ${ }^{9}$

‡Categories suggested by Jaekel et al. ${ }^{11}$

$\S$ Born between 1 April and 31 August.

BiB, Born in Bradford; EYFSP, Early Years Foundation Stage Profile; GCSE, General Certificate of Secondary Education; GLD, Good Level of Development.

\section{Socioeconomic and educational factors}

Socioeconomic influences were measured using the mother's self-reported highest level of educational qualification (maternal highest qualification, MHQ), equivalised if educated abroad, and whether they received means-tested benefits (MTB). Both were recorded as part of the $\mathrm{BiB}$ cohort maternal baseline questionnaire. ${ }^{8}$ These criteria have been used to estimate socioeconomic status within the $\mathrm{BiB}$ cohort in previously published research. ${ }^{10}$ From the local authority educational records, a measure of whether a child was known to speak English as an additional language (EAL) was also captured (coded as: yes/no/ don't know).

\section{Statistical analysis}

Logistic regression, using a generalised linear modelling (GLM) method (in R V.3.4.3), was used to estimate the relationship 
between gestational age (in completed weeks) and a child's likelihood of not achieving a GLD on the EYFSP. An initial set of exploratory analyses (see online supplementary table S1) fitted this relationship with linear (online supplementary table S1, step 1 ) and then polynomial, quadratic and then cubic terms (steps 2 and 3, respectively) because previous research has suggested gestation has a non-linear relationship with certain developmental outcomes. ${ }^{11}$

A first set of analyses looked specifically at predictors of not achieving a GLD within children whose date of birth had not resulted in them starting school a year earlier than they otherwise would have had they been born at term. In this sample, regression models tested the effect of gestational age after controlling for a child's AMoB (table 3, step 2), then in a subsequent third step tested whether there was a significant moderating effect of $\mathrm{AMoB}$ on gestational age. A further two adjusted versions of this analysis were run (see online supplementary table S2, steps 2 and 3 ). In the first of these, additional perinatal covariates (parity, gender, SGA and LGA) were controlled for alongside AMoB to see if the effects of gestational age remained after controlling for these factors. In the second, the model adjusted for these perinatal factors (parity, gender, SGA and LGA) as well as additional socioeconomic and educational factors (MHQ, MTB and EAL).

A second set of analyses tested for specific differences in the likelihood of not achieving a GLD in the EAS cases, compared with (1) preterm children not born during the summer months, June-August, hereafter referred to as 'summer-born' (ie, controlling for gestational but not chronological maturity); (2) term summer-born children (ie, controlling for chronological but not gestational maturity); and (3) preterm summer-born children whose year of school entry was unaffected by prematurity (ie, controlling for both types of maturity).

As with the preceding analyses, relationships between early school entry and the GLD outcome were first investigated as a univariable analysis (step 1 in online supplementary tables S3S5) before successively adjusting for further perinatal (steps 2) and socioeconomic and educational covariates (steps 3). The only differences were that in the models comparing EAS against other preterm children, gestational age was entered as an additional covariate alongside the other perinatal factors, while in the model comparing EAS against other (non-premature) summerborn children $\mathrm{AMoB}$ was entered. Prior to conducting adjusted analyses, to mitigate for loss of power in these analyses created by missing at random data, values for missing data within covariates were estimated using a multiple imputation chained equation technique, implemented using the Multivariate Imputation by Chained Equations (MICE) package in R. ${ }^{12}$

\section{RESULTS}

Seven children failed to meet the inclusion criteria of starting school in the standard academic year anticipated by their birth date. None of these children were preterm. All seven children started school a year late, which is usually only permitted by local authorities in exceptional circumstances, as suggested by these excluded cases all being recorded as having SEN.

All the children who entered school an academic year earlier than anticipated during pregnancy (EAS) were categorically 'preterm births', representing $8.5 \%$ of the preterm births in the sample (53 out of 624). No children were found to start 'late' due to being born after their estimated date of delivery. Five cases of EAS were lost to further analysis because of complete but uncategorisable responses for covariates (eg, a response of 'foreign unknown' for MHQ). Comparison of the demographic make-up of the 48 remaining cases of EAS with the other groups is presented in table 2 .

\section{Gestational age and AMoB}

The most parsimonious model fit for gestational age as predictor, in this data set, was found to be linear. There were no statistically significant improvements in model fit from estimating further polynomial parameters (tested using $-2 \log$ likelihood ratio tests, all $\mathrm{p}>0.05$ ). Thus all subsequent analyses modelled gestational age as a linear predictor of GLD. Full tabular summaries of this and further analyses are presented across table 3 and online supplementary tables S1-S5.

Logistic regression (table 3 ) showed that gestational age, in weeks, was a significant predictor of whether a child attained a GLD on the EYFSP $\left(\chi^{2}(1)=651.7, p<0.001\right)$. This effect persisted after controlling for the significant effect of $\mathrm{AMoB}$ $\left(\chi^{2}(1)=47.2, p<0.001\right)$. ORs indicated that for each successive week that a child was born early, their odds of not attaining a GLD increased by 1.09 (95\% CI 1.06 to 1.11). In addition, for every month later in the academic year the child was born, these odds also increased by 1.17 (95\% CI 1.16 to 1.18). However, no significant improvement in model fit arose from adding an interaction between gestational age and $\mathrm{AMoB}$ to this model $\left(\chi^{2}(1)=0.2, p=0.7\right)$, suggesting $\mathrm{AMoB}$ did not moderate the risks posed by reduced gestational age.

Adjustment for additional covariates did not materially affect the estimates of these effects, with the odds for both the effects of gestational age 1.09 (95\% CI 1.06 to 1.12) and AMoB 1.19 (95\% CI 1.17 to 1.20 ) still comparable in magnitude. Illustrations of these effects, after fully adjusting for covariates, are presented in figure 1.

\section{EAS versus comparator groups}

Children starting school a school year earlier than anticipated during pregnancy were less likely to achieve a GLD compared with (1) other children born preterm (fully adjusted OR 5.51 (2.85-14.25)); (2) term summer births (fully adjusted OR 3.02 (1.49-6.79)); and (3) preterm summer births who remained within their anticipated school year (fully adjusted OR 3.64 (1.27-11.48)). These effects again remained after adjustment (see figure 2 and online supplementary tables S3-S5).

\section{DISCUSSION}

Our findings indicate differences in the odds that 5-year-old children will exhibit the level of development expected by the national education system due to both gestational and schoolentry age. The results are consistent with earlier research ${ }^{7}$ in that the odds of not achieving a GLD almost double in children born in the final (vs the first) month of an academic school year. The incremental effect of gestational age each week was such that for a child born at 34 weeks' gestation, there was an approximate doubling of the odds of them not attaining the level of expected development, compared with a child born at term.

In particular, children who entered school a year early due to being born premature appeared to be at substantial disadvantage. This group's odds of not showing a GLD were more than three-and-a-half times greater than even the summer-born preterm children who did not start school a year early.

The specific 'double disadvantage' of prematurity causing a child to be chronologically young within the school year has rarely been considered in previous research. Odd et $a l^{4}$ report a relationship between preterm birth and poorer academic attainment at 7 and 16 years of age, which disappeared when 
Table 2 Comparison of demographics of children who enter school a year early due to premature birth 'Early Academic Starts' versus preterm births outwith June-August, term June-August births and preterm births in June-August not entering school early

\begin{tabular}{|c|c|c|c|c|}
\hline & $\begin{array}{l}\text { Early Academic } \\
\text { Starts } \\
\mathrm{n}=48\end{array}$ & $\begin{array}{l}\text { Preterm not June-August } \\
\text { births } \\
n=457\end{array}$ & $\begin{array}{l}\text { June-August term births } \\
\mathrm{n}=1972\end{array}$ & $\begin{array}{l}\text { Preterm + June-August } \\
\text { not EAS } \\
n=64\end{array}$ \\
\hline \multicolumn{5}{|l|}{ Educational factors } \\
\hline EYFSP, $n(\%)$ 'meeting GLD'* & $9(19)$ & $239(52)$ & $841(43)$ & $24(38)$ \\
\hline English as an additional language, $\mathrm{n}(\%)$ & $19(40)$ & $191(42)$ & $973(49)$ & $40(63)$ \\
\hline \multicolumn{5}{|l|}{ Perinatal factors } \\
\hline \multicolumn{5}{|l|}{ Gestational age (weeks), n (\%)† } \\
\hline$<32$ & $10(21)$ & $61(13)$ & - & $6(9)$ \\
\hline $32-33$ & $6(13)$ & $49(11)$ & - & $4(6)$ \\
\hline $34-36$ & $32(67)$ & $347(78)$ & - & $54(84)$ \\
\hline $37-38$ & - & - & $458(23)$ & - \\
\hline $39-41$ & - & - & $1478(75)$ & - \\
\hline$>42$ (late term) & - & - & $36(2)$ & - \\
\hline Small for gestational age, $\mathrm{n}(\%) \ddagger$ & $5(10)$ & $54(12)$ & $255(13)$ & $7(11)$ \\
\hline Large for gestational age, $\mathrm{n}(\%) \neq$ & $2(4)$ & $42(9)$ & $144(7)$ & $4(6)$ \\
\hline Sex ratio (male:female) & $50: 50$ & $47: 53$ & $47: 53$ & $47: 53$ \\
\hline Parity, median (range) $\ddagger$ & $1(0-3)$ & $1(0-8)$ & $1(0-8)$ & $1(0-5)$ \\
\hline \multicolumn{5}{|l|}{ Socioeconomic factors } \\
\hline Mother receiving means-tested benefits, $\mathrm{n}(\%) \ddagger$ & $24(50)$ & $197(43)$ & $852(43)$ & $27(42)$ \\
\hline \multicolumn{5}{|l|}{ Maternal educational level (equivalised), $n(\%) \ddagger$} \\
\hline Higher than A level & $11(23)$ & $119(26)$ & $520(26)$ & $14(22)$ \\
\hline A level or equivalent & $9(19)$ & $77(17)$ & $302(15)$ & $11(17)$ \\
\hline 5 GCSEs or equivalent & $17(35)$ & $131(29)$ & $690(35)$ & $23(38)$ \\
\hline$<5$ GCSEs or equivalent & $11(23)$ & $130(28)$ & $460(23)$ & $16(25)$ \\
\hline
\end{tabular}

*As defined by Cotzias and Whitehorn. ${ }^{9}$

tCategories suggested by Jaekel et al. ${ }^{11}$

$¥$ Contains imputed values for missing data.

EAS, Early Academic Starts; EYFSP, Early Years Foundation Stage Profile; GCSE, General Certificate of Secondary Education; GLD, Good Level of Development.

children who started school a year early due to preterm birth were excluded from analysis. Johnson et al ${ }^{2}$ showed that children born $\leq 25$ weeks' gestation who entered school a year earlier than anticipated were more likely to have SEN but did not show differences on standardised academic test scores at age 11 years. ${ }^{2}$ Jaekel et al's ${ }^{13}$ studied a cohort of German schoolchildren, finding no differences between children with and without delayed school entry on attainment at the end of the first year of school. However, those children whose school entry was deferred performed worse on standardised assessments at age 8 years. This may reflect a negative impact of delayed entry or that the most profoundly affected children are over-represented in the delayed entry group.

Further research is needed to gain a clearer understanding of why a symbiotic relationship between preterm birth and school-entry age exists in EAS. Norbury et $a l^{7}$ report that, in conjunction with being less likely to reach the expected level on the EYFSP, the youngest children in a school year typically also exhibit more inter-related behavioural and language difficulties. Such difficulties also co-occur more frequently in children born moderate-to-late preterm in early childhood. ${ }^{14}$ Thus, it may be that the increased liklihood of difficulties faced by children who

Table 3 Hierarchical logistic regression of effects of gestational age (in weeks) on failing to attain a Good Level of Development on the EYFSP after controlling and moderating for the additional effects of academic month of birth

\begin{tabular}{|c|c|c|c|}
\hline & Step 1 & Step 2 & Step 3 \\
\hline Variable & OR $(95 \% \mathrm{Cl})$ & OR $(95 \% \mathrm{Cl})$ & OR $(95 \% \mathrm{Cl})$ \\
\hline Academic month of birth & $1.17(1.15 \text { to } 1.18)^{* * *}$ & $1.17(1.16 \text { to } 1.18)^{\star * *}$ & $1.17(1.16 \text { to } 1.18)^{* * *}$ \\
\hline Gestational age (in weeks) & & $1.09(1.06 \text { to } 1.11)^{\star * *}$ & $1.08(1.06 \text { to } 1.11)^{* * *}$ \\
\hline Interactiont & & & 0.99 (0.99 to 1.01 ) \\
\hline $\mathrm{R}^{2}$ (Hosmer-Lemeshow) & 0.047 & 0.050 & 0.050 \\
\hline $\mathrm{R}^{2}$ (Cox-Snell) & 0.061 & 0.065 & 0.065 \\
\hline $\mathrm{R}^{2}$ (Nagelkerke) & 0.082 & 0.088 & 0.088 \\
\hline$\chi^{2} \ddagger$ & $651.7^{* * *}$ & $47.2^{* * *}$ & 0.2 \\
\hline
\end{tabular}

$\mathrm{n}=10337$.

${ }^{*} \mathrm{P}<.05,{ }^{* *} \mathrm{p}<0.01,{ }^{* * *} \mathrm{p}<0.001$.

tGestational age $\times$ academic month of birth.

\#Significance denotes change in model fit from previous step in the hierarchical model.

EYFSP, Early Years Foundation Stage Profile. 
A
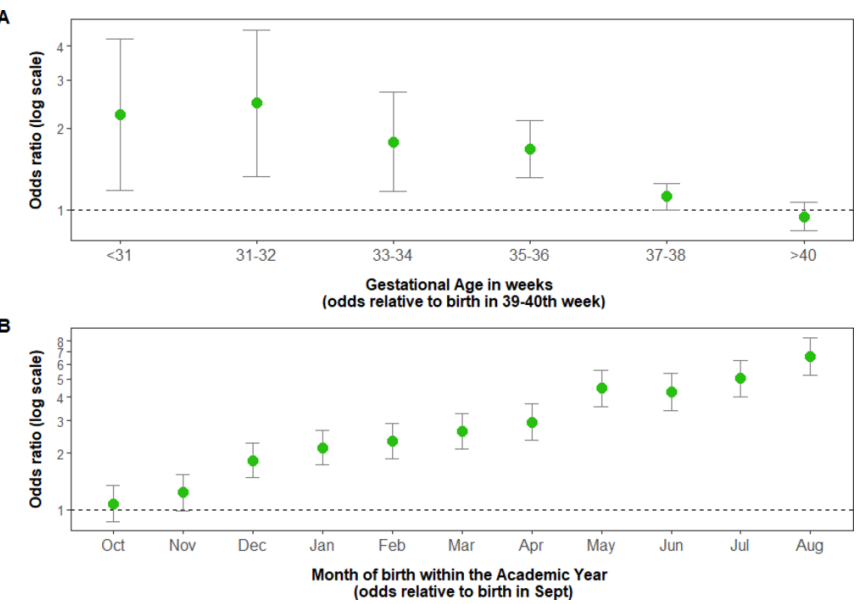

Figure 1 The effects of (A) gestational age in weeks and (B) academic month of birth on the odds of failing to achieve a Good Level of Development after fully adjusting for covariates.

start school early due to premature birth relate to these risk factors converging.

Meanwhile, a recent study using parental questionnaires showed only a small proportion of moderate-to-late preterm children had problems typically associated with prematurity. ${ }^{15}$ Our findings suggest the contrary and add weight to arguments for more support for moderate-to-late preterm children, previously presumed to require no additional surveillance. ${ }^{5}$ Indeed, these results illustrate differences in educationally relevant aspects of a child's development at an earlier age than previous research. ${ }^{24}$ As part of the $\mathrm{BiB}$ cohort study, we will be following these children's developmental progress over their life course and investigating the longer term effects on educational and economic attainment.

\section{Implications for practice and policy}

The assessment of childhood development we used can be treated as an estimate of a child's capacity to cope with the transition into formal education ${ }^{9}$; thus, our findings suggest the need for a more proactive approach by health and education



Figure 2 The odds of failing to attain a GLD due to being an EAS compared with (i) preterm non-summer-born children, (ii) non-preterm summer-born children and (iii) preterm summer-born children who remained within the academic year anticipated during pregnancy. EAS, Early Academic Starts; EYFSP, Early Years Foundation Stage Profile; GLD, Good Level of Development. professionals in supporting gestationally immature children through this transition. Possible methods for doing this include providing learning resources to teachers to help them support children born preterm in the classroom (such as those developed by Johnson and colleagues ${ }^{16}$ ), tailored advice to families, and greater use of routine data linkage to more easily allow at-risk children to be monitored and supported longitudinally, across health and education services. Such interventions may be vitally important in mitigating the cascading risks that preterm birth poses later for mental health, cognitive development and academic attainment. ${ }^{17}$

We found no evidence of age within a given academic year interacting with the preterm risk, and while this was not an analysis of the direct effect of delaying entry (this analysis was not possible due to too few cases of delayed entry in the cohort), this lack of a moderating effect may suggest that simply delaying the age of school entry per se may not be the best way to support children born prematurely.

\section{CONCLUSIONS}

We found strong independent effects of chronological age and prematurity on a child's developmental readiness for schooling and that children starting school a year earlier than anticipated during pregnancy are 'doubly disadvantaged'. This work provides further evidence of the interplay between health and education and is intended as a first step away from arbitrary decision making, instead allowing health and education departments to work together to guide where resources should be directed. We hope this will become an example of progress towards evidencebased policy making - an approach already being adopted by Bradford local authority.

Acknowledgements Born in Bradford is only possible because of the enthusiasm and commitment of the children and parents in BiB. We are grateful to all the participants, health professionals and researchers who have made Born in Bradford happen. Our thanks to Kate Pickett and Derek Tuffnell for their invaluable comments during internal peer review of our project at the proposal stage.

Contributors ICMJE criteria for authorship read and met: KJP, BK, TAS, MM-W, $J W$, LJBH. Agree with the manuscript's results and conclusions: KJP, BK, TAS, MM-W, JW, LJBH. Designed the study: KJP, TAS, LJBH. Analysed the data: LJBH, BK. Collected data/did experiments for the study: not applicable (secondary data analysis). Wrote the first draft of the paper: KJP. Contributed to the writing of the paper: KJP, BK, TAS, MM-W, JW, LJBH.

Funding BiB receives core infrastructure funding from the Wellcome Trust (WT101597MA) and the National Institute for Health Research (NIHR) under its Collaboration for Applied Health Research and Care (CLAHRC) for Yorkshire and Humber and Clinical Research Network (CRN) research delivery support. Linkages with education data for this cohort are further supported by a joint grant from the UK Medical Research Council and UK Economic and Social Science Research Council (MR/N024397/1) and through the Opportunity Areas programme in Bradford. The views expressed are those of the author(s), and not necessarily those of the NHS, the NIHR, the Department of Health and Social Care, the Bradford Opportunity Area Partnership Board, the City of Bradford Metropolitan District Council, or the Department of Education.

Disclaimer The views expressed are those of the author(s) and not necessarily those of the NHS, the NIHR, the Department of Health and Social Care, the Bradford Opportunity Area Partnership Board, the City of Bradford Metropolitan District Council, or the Department of Education.

Competing interests None declared.

Patient consent for publication Not required.

Ethics approval Ethics approval was obtained for the main platform study from the Bradford Research Ethics Committee (Ref 07/H1302/112)

Provenance and peer review Not commissioned; internally peer reviewed.

Data sharing statement All the data we have used are available on request from the BiB longitudinal cohort study. Access to this data is available on request via this link (https://borninbradford.nhs.uk/research/how-to-access-data/). We (the authors) do not have permission to republish independently the data shared with us by the 
cohort to conduct our study, as per the conditions of the data sharing agreement we signed with $\mathrm{BiB}$ in order to be granted access to their data.

Open access This is an open access article distributed in accordance with the Creative Commons Attribution 4.0 Unported (CC BY 4.0) license, which permits others to copy, redistribute, remix, transform and build upon this work for any purpose, provided the original work is properly cited, a link to the licence is given, and indication of whether changes were made. See: https://creativecommons.org/ licenses/by/4.0/.

ORCID iD

Katherine J Pettinger http://orcid.org/0000-0002-4749-0866

\section{REFERENCES}

1 MacKay DF, Smith GC, Dobbie R, et al. Gestational age at delivery and special educational need: retrospective cohort study of 407,503 schoolchildren. PLoS Med 2010;7:e1000289.

2 Johnson S, Hennessy E, Smith R, et al. Academic attainment and special educational needs in extremely preterm children at 11 years of age: the EPICure study. Arch Dis Child Fetal Neonatal Ed 2009;94:F283-9.

3 Odd D, Evans D, Emond A. Preterm birth, age at school entry and educational performance. PLoS One 2013;8:e76615.

4 Odd D, Evans D, Emond A. Preterm birth, age at school entry and long term educational achievement. PLoS One 2016;11:e155157.

5 The National Institute for Health and Care Excellence (NICE). Developmental followup of children and young people born preterm. 2017 https://www.nice.org.uk/ guidance/ng72

6 Peacock PJ, Henderson J, Odd D, et al. Early school attainment in late-preterm infants. Arch Dis Child 2012;97:118-20
7 Norbury CF, Gooch D, Baird G, et al. Younger children experience lower levels of language competence and academic progress in the first year of school: evidence from a population study. J Child Psychol Psychiatry 2016;57:65-73.

8 Wright J, Small N, Raynor P, et al. Cohort Profile: the Born in Bradford multi-ethnic family cohort study. Int J Epidemiol 2013;42:978-91.

9 Cotzias E, Whitehorn T. Topic note: results of the Early Years Foundation Stage Profile (EYFSP). Pilot: Research Report, 2013.

10 Kelly B, Williams S, Collins S, et al. The association between socioeconomic status and autism diagnosis in the United Kingdom for children aged 5-8years of age: Findings from the Born in Bradford cohort. Autism 2019;23:131-40.

11 Jaekel J, Baumann N, Wolke D. Effects of gestational age at birth on cognitive performance: a function of cognitive workload demands. PLoS One 2013;8:e65219.

12 Buuren S, Groothuis-Oudshoorn K. mice : Multivariate Imputation by Chained Equations in R. J Stat Softw 2011;45:1-67.

13 Jaekel J, Strauss VY, Johnson S, et al. Delayed school entry and academic performance: a natural experiment. Dev Med Child Neurol 2015;57:652-9.

14 Potijk MR, de Winter AF, Bos AF, et al. Co-occurrence of developmental and behavioural problems in moderate to late preterm-born children. Arch Dis Child 2016;101:217-22.

15 Johnson S, Waheed G, Manktelow BN, et al. Differentiating the preterm phenotype: distinct profiles of cognitive and behavioral development following late and moderately preterm birth. J Pediatr 2018;193:85-92.

16 Johnson S, Clayton S, Cragg L, et al. Preterm birth information for education professionals. 2019 https://www.nottingham.ac.uk/helm/dev/prism/ (accessed4 Jun 2019).

17 Allotey J, Zamora J, Cheong-See F, et al. Cognitive, motor, behavioural and academic performances of children born preterm: a meta-analysis and systematic review involving 64061 children. BJOG 2018;125:16-25. 